\title{
Cardiovascular disease and healthy ageing
}

\author{
Kathleen M. Mooney ${ }^{1}$ and Mark T. Mc Auley ${ }^{2 *}$ \\ ${ }^{1}$ Faculty of Health and Social Care, Edge Hill University, Ormskirk, Lancashire, L39 4QP, UK \\ ${ }^{2}$ Faculty of Science and Engineering, Thornton Science Park, University of Chester, CH2 4NU, UK
}

\begin{abstract}
Cardiovascular diseases are main cause of morbidity and mortality in the Western World. Cardiovascular disease increases in its prevalence with age and the burden of this condition is set to increase with an Ageing global population. There are many factors that impact cardiovascular disease risk. The aim of this brief commentary is to explore some of these factors; specifically, we will examine the role of social status, nutrition and, psychological stress in modulating cardiovascular disease risk. Our aim is to emphasise the multidimensional nature of this condition and to stress that a more complete understanding of the mechanisms which underpin its pathology can only be achieved by adopting an integrated approach which treats the progression of this disease in a more holistic fashion.
\end{abstract}

\section{Introduction}

The global population is gradually ageing. With an ageing population there comes an increase in the prevalence age related disease. Of the diseases of ageing those conditions of the heart and circulatory system, which are collectively known as cardiovascular disease (CVD), are the most common. The growth in prevalence of CVD has implications for governments, health professionals, and those likely to suffer from the condition as the cost of treating and caring for individuals with CVD is set to escalate. This will no doubt impact the health and well-being of older individuals whose treatment may be curtailed or compromised due to the financial burden of caring for them. This problem may prevent older people from benefitting from the healthy extra few years of life which they would otherwise gain. Therefore, it is logical that a better understanding of the risk factors that underpin CVD risk is achieved. Risk factors can be broadly categorised into extrinsic and intrinsic. Extrinsic factors include physical inactivity, social status, the environment, nutrition, and psychological stress. Intrinsic factors include genetic/epigenetic status, perturbations in physiological systems, such as lipid biomarkers, blood pressure and a variety of hormones. In this short communication we will very briefly examine some of these risk factors and we will emphasise that a combination of factors is ultimately responsible for modulating CVD risk. Our overarching aim is to encourage a more integrated interpretation of ageing and the role it has to play in CVD progression [1-3].

\section{The role of dietary lipids}

Diet is a significant adaptable determinant of healthy ageing. In recent years a wide variety of studies have scrutinised micro and macronutrients in order to find the optimal dietary balance that minimise the insidious effects of ageing. In particular a large number of studies have examined the effect of dietary lipids on CVD risk, due to their intimate relationship with lipid metabolism. The relationship between dietary cholesterol (DC) and CVD is a controversial one. For instance, certain studies have shown that DC is a risk factor for CVD, while others have found no association (reviewed in [4]). Part of the problem is that individuals vary significantly in their responses to DC. Based on our findings from whole-body mathematical modelling [5] we are of the opinion that these inter-individual variations are at least partly due to the heterogeneity in cholesterol absorption, that exists among healthy individuals [6]. Despite the fact that the role of DC in CVD remains controversial; there is less ambiguity when it comes to examining the metabolic impact of dietary saturated fatty acids (SFAs) have on CVD risk. SFAs are widely regarded to increase CVD risk, due to their effect on low density lipoprotein cholesterol (LDL-C) (reviewed in [7]). Conversely n-6 and n-3 polyunsaturated fatty acids are inversely related to CVD mortality [8]. Thus, CVD risk from diet can in part be assumed to be a combination of the metabolic effects of these macronutrients. Studying their molecular, biochemical, physiological and whole body effects requires integrated frameworks which are capable of dealing with this level of complexity [9].

\section{Is dietary fibre being overlooked?}

Recently a comprehensive meta-analysis found that total dietary fibre intake is inversely correlated with risk of CVD [10]. This relationship could be modulated by the favourable effects dietary fibre has on blood lipid profile. For example, a previous meta-analysis found a correlation between the consumption of soluble fibre and a decrease in LDL-C levels [11]. This meta-analysis of 67 controlled trials found that $3 \mathrm{~g}$ of soluble fibre from oats (3 daily servings of oatmeal, $28 \mathrm{~g}$ each) can decrease total and LDL-C significantly. Perhaps we have overlooked dietary fibre lately as the blood cholesterol lowering focus has been on plant sterols. Plant sterols are naturally occurring compounds, which are structurally related to cholesterol, differing only in the structure of their side chains [12]. Consumption of 1.8$2.0 \mathrm{~g} /$ day of plant sterols has in recent years been shown to lower both total and LDL-C concentrations by $10 \%-15 \%$ in a variety of different population groups [13]. Normal daily intakes of plant sterols are in the range $170-360 \mathrm{mg} /$ day [14]. Several studies have indicated that plant sterols reduce cholesterol absorption by $30 \%-50 \%$, although the

Correspondence to: Dr. Mark Mc Auley, Faculty of Science and Engineering, Thornton Science Park, University of Chester, CH2 4NU, UK, Tel: 01244 513927; E-mail: m.mcauley@chester.ac.uk

Received: May 24, 2015; Accepted: June 14, 2015; Published: June 16, 2015 
precise biological mechanism(s) responsible for this remains unclear. However, a wide variety of processes have been suggested, including the interference of trans-intestinal cholesterol excretion (reviewed in [15]).

\section{Physical activity}

Physical activity (PA) frequently decreases with age due to a reduction in the pace of life. However, the importance of staying physically active cannot be underestimated. There is significant evidence, from a broad range of studies which suggest an inverse relationship between PA and CVD risk. This amelioration could be induced by an improvement in blood lipid profile. For example, in a classic meta-analysis Leon et al. (2001) reviewed 51 human intervention studies examining the effects of at least 12 weeks of PA on blood lipid profile in men and women from 1987-2000 [16]. The authors reported a lipid profile improvement in response to PA in nearly half of the studies reviewed. It has also been suggested that lipid profile is improved through the activation of lipoprotein lipase a key enzyme involved in fatty acid metabolism, which stimulates the clearance of triglyceride-rich lipoproteins to supply free fatty acids to exercising muscle. In our opinion there is a growing need to investigate the doseresponse relationship between physical activity and CHD/CVD risk in older people. If this relationship could be further understood then appropriate PA regimes could be tailored for older people based on individual circumstance.

\section{How does social status impact CVD risk?}

It has long been accepted that inequalities in social status have an impact on CVD risk. Within the European Union (EU) significant gaps persist in health equality. Individuals from lower social backgrounds have a significantly reduced life expectancy. According to the most recent available demographic data, a child born in England or Wales between 2010 and 2012 can expect to live to 79.1 years if male and 89.2 years if female [17]. However, males born within the Scottish city of Glasgow during the same period have a life expectancy of 72.6 years [18]. Such differences are not confined to the UK, the EU Working Group on Socioeconomic Inequalities in Health; compared 13 European countries based on their inequalities with respect to morbidity and mortality [19]. This study found that relative inequalities in premature mortality have continued to rise in most European countries, and since the 1990s, the contrast between the South (with smaller inequalities) and the East (with larger inequalities) has become increasingly significant. Higher social status is not universally beneficial. In developing countries, higher social status has been associated with an increased CVD risk factor profile [20]. This is potentially due to the adoption of a westernized lifestyle which is characterized by physical inactivity, smoking and poor diet. It is likely this is a contributing factor to the emergence of the CVD epidemic that has taken place in developing countries in the last half century.

\section{Stress and cortisol}

Exposure to psychological stress also contributes to CVD risk. The impact of psychological stress on CVD health could be mediated by hormonal changes which have been implicated in perturbing lipid metabolism, (reviewed in [21]). Cortisol is a glucocorticoid hormone whose release is provoked by stress. The hormone is synthesised in the adrenal gland and released from the pituitary. It acts ubiquitously throughout the body by binding to glucocorticoid receptors where it performs a wide variety of roles, including acting as an antagonist to insulin by provoking gluconeogenesis; it also promotes the breakdown of lipids, and a wide variety of other metabolites [22]. Despite the essential role of cortisol in maintaining the normal physiology of the body after stress, continual exposure to cortisol has been suggested to disrupt normal metabolism. For example, cortisol has been implicated as a pathophysiological mediator in idiopathic obesity [23] and has also been associated with an unfavourable lipid profile in women [24]. Cortisol excess also impacts a broad range of other parameters of cardiovascular health [25]. Recently, we used mathematical modelling to show that both acute and chronic levels of cortisol have a profound impact on brain ageing. It would be worthwhile adopting a similar framework to explore the long term impact of elevated cortisol on CVD risk [26].

\section{Genetic and epigenetic factors}

A plethora of genetic polymorphisms have been associated with CVD risk [27]. If we focus on lipid metabolism mutations in cholesteryl ester transfer protein, an enzyme that is essential for reverse cholesterol transport, could lessen the risk of developing ischemic heart disease [28]. Similarly, mutations in the gene coding for Apolipoprotein E have an established association with CVD risk. apo $\mathrm{E}$ is a protein associated with chylomicrons, very low density lipoproteins, and high density lipoprotein-cholesterol. It acts as a ligand for the LDL receptor. The apo E locus has 3 common alleles, E4, E3, and E2. apo E deficiency results in high levels of cholesterol-enriched lipoproteins, with the apo E4 variant having the most significant impact on lipid metabolism, due to its association with elevated LDL-C [29].

Epigenetic factors have also been implicated in the progression of CVD. Epigenetics is the study of heritable alterations in gene expression that occur without changes to the DNA sequence. Epigenetic mechanisms include DNA methylation and histone modifications, with the former being best understood. DNA methylation acts as a marker during embryonic development, as methyl groups act as indicators for foetal development [30]. Once these tissue specific methylation patterns have been established, their maintenance becomes crucial. The primary reason for this is that throughout life DNA methylation plays a vital role in the regulation of gene expression [31]. However, during ageing DNA methylation patters alter significantly [32]. The consequences of this are that age related changes to methylation patterns have been associated with a variety of diseases including CVD [33]. For instance, a recent study found an association between DNA methylation and a number of genes implicated in CVD [34].

\section{Conclusions}

The ultimate goal of research into healthy ageing should be to understand the ageing process to the extent where novel strategies that delay or even prevent the onset of conditions such as CVD can be implemented. Developing novel strategies will require a more integrated understanding of the ageing process and a holistic appreciation of the wide variety of both intrinsic and extrinsic factors that contribute to CVD risk. How successful we are in implementing these interventions may ultimately determine the quality of life in very old age. In so doing we may not rid humanity of age related disease, but may significantly mitigate its impact.

\section{References}

1. Mc Auley MT, Mooney KM, Angell PJ, Wilkinson SJ (2015) Mathematical modelling of metabolic regulation in aging. Metabolites 5: 232-251. [Crossref]

2. Mc Auley MT, Jones J, Wilkinson D, Kirkwood T (2005) Modelling Lipid Metabolism to Improve Healthy Ageing. BMC Bioinformatics 6: 21 . 
3. Mc Auley MT, Mooney KM (2015) Computational systems biology for aging research. Interdiscip Top Gerontol 40: 35-48. [Crossref]

4. Lecerf JM, de Lorgeril M (2011) Dietary cholesterol: from physiology to cardiovascular risk. Br J Nutr 106: 6-14. [Crossref]

5. Mc Auley MT, Wilkinson DJ, Jones JJ, Kirkwood TB (2012) A whole-body mathematical model of cholesterol metabolism and its age-associated dysregulation. BMC Syst Biol 6: 130. [Crossref]

6. Bosner MS, Lange LG, Stenson WF, Ostlund RE Jr (1999) Percent cholesterol absorption in normal women and men quantified with dual stable isotopic tracers and negative ion mass spectrometry. J Lipid Res 40: 302-308. [Crossref]

7. Siri-Tarino PW, Sun Q, Hu FB, Krauss RM (2010) Saturated fatty acids and risk of coronary heart disease: modulation by replacement nutrients. Curr Atheroscler Rep 12: 384-390. [Crossref]

8. Kris-Etherton PM, Harris WS, Appel LJ; American Heart Association Nutrition Committee. (2002) Fish consumption, fish oil, omega-3 fatty acids, and cardiovascular disease. Circulation 106: 2747-2757. [Crossref]

9. Mc Auley MT, Mooney KM (2014) Computationally Modeling Lipid Metabolism and Aging: A Mini-review. Comput Struct Biotechnol J 13: 38-46. [Crossref]

10. Threapleton DE, Greenwood DC, Evans CE, Cleghorn CL, Nykjaer C, et al. (2013) Dietary fibre intake and risk of cardiovascular disease: systematic review and metaanalysis. BMJ 347: f6879. [Crossref]

11. Brown L, Rosner B, Willett WW, Sacks FM (1999) Cholesterol-lowering effects of dietary fiber: a meta-analysis. Am J Clin Nutr 69: 30-42. [Crossref]

12. Genser B, Silbernagel G, De Backer G, Bruckert E, Carmena R, et al. (2012) Plant sterols and cardiovascular disease: a systematic review and meta-analysis. Eur Heart J33: 444-451. [Crossref]

13. Katan MB, Grundy SM, Jones P, Law M, Miettinen T, et al. (2003) Efficacy and safety of plant stanols and sterols in the management of blood cholesterol levels. Mayo Clin Proc 78: 965-978. [Crossref]

14. de Vriesa JHM, Jansenb A, Kromhoutb D, van de Bovenkampa P, van Staverena WA, et al. (1997) The fatty acid and sterol content of food composites of middle-aged in seven countries. J Food Compos Anal 10: 115-141.

15. De Smet E, Mensink RP, Plat J (2012) Effects of plant sterols and stanols on intestina cholesterol metabolism: suggested mechanisms from past to present. Mol Nutr Food Res 56: 1058-72. [Crossref]

16. Leon AS, Sanchez OA (2001) Response of blood lipids to exercise training alone or combined with dietary intervention. Med Sci Sports Exerc 33: S502-S515. [Crossref]

17. UK Office for National Statistcs, Statistical Bulletin: Life expectancy at birth and at age 65 for local areas in England and Wales, 2010-12 2013.

18. Statistics, U.O.f.N. 2014; Available from: http://www.ons.gov.uk/index.htm\#tabNational-Life-Expectancy.
19. Mackenbach JP, Kulhánová I, Menvielle G, Bopp M, Borrell C, et al. (2015) Trends in inequalities in premature mortality: a study of 3.2 million deaths in 13 European countries. J Epidemiol Community Health 69: 207-217. [Crossref]

20. Samuel P, Antonisamy B, Raghupathy P, Richard J, Fall CH (2012) Socio-economic status and cardiovascular risk factors in rural and urban areas of Vellore, Tamilnadu, South India. Int J Epidemiol 41: 1315-1327. [Crossref]

21. Mc Auley MT, Mooney KM (2014) Lipid metabolism and hormonal interactions: impact on cardiovascular disease and healthy aging. Expert Review of Endocrinology \& Metabolism 9: 357-367.

22. Turcu AF, Auchus RJ (2015) Adrenal Steroidogenesis and Congenital Adrenal Hyperplasia. Endocrinol Metab Clin North Am 44: 275-296. [Crossref]

23. Björntorp P, Rosmond R (2000) Obesity and cortisol. Nutrition 16: 924-936. [Crossref]

24. Walker BR, Soderberg S, Lindahl B, Olsson T (2000) Independent effects of obesity and cortisol in predicting cardiovascular risk factors in men and women. J Intern Med 247: 198-204. [Crossref]

25. Whitworth JA, Williamson PM, Mangos G, Kelly JJ (2005) Cardiovascular consequences of cortisol excess. Vasc Health Risk Manag 1: 291-299. [Crossref]

26. McAuley MT, Kenny RA, Kirkwood TB, Wilkinson DJ, Jones JJ, et al. (2009) A mathematical model of aging-related and cortisol induced hippocampal dysfunction. BMC Neurosci 10: 26. [Crossref]

27. Cambien F, Tiret L (2007) Genetics of cardiovascular diseases: from single mutation to the whole genome. Circulation 116: 1714-1724. [Crossref]

28. Corbex M, Poirier O, Fumeron F, Betoulle D, Evans A, et al. (2000) Extensive association analysis between the CETP gene and coronary heart disease phenotype reveals several putative functional polymorphisms and gene-environment interaction. Genet Epidemiol 19: 64-80. [Crossref]

29. Zhang Y, Tang HQ, Peng WJ, Zhang BB, Liu M (2015) Meta-analysis for the association of apolipoprotein $\mathrm{E} \varepsilon 2 / \varepsilon 3 / \varepsilon 4$ polymorphism with coronary heart disease. Chin Med J (Engl) 128: 1391-1398. [Crossref]

30. Smith ZD, Chan MM, Humm KC, Karnik R, Mekhoubad S, et al. (2014) DNA methylation dynamics of the human preimplantation embryo. Nature 511: 611-615. [Crossref]

31. Jaenisch R, Bird A (2003) Epigenetic regulation of gene expression: how the genome integrates intrinsic and environmental signals. Nat Genet 33 Suppl: 245-254. [Crossref]

32. Jung M, Pfeifer GP (2015) Aging and DNA methylation. BMC Biol 13: 7. [Crossref]

33. Baccarelli A, Rienstra M, Benjamin EJ (2010) Cardiovascular epigenetics: basic concepts and results from animal and human studies. Circ Cardiovasc Genet 3: 567573. [Crossref]

34. Kim M, Long TI, Arakawa K, Wang R, Yu MC, et al. (2010) DNA methylation as a biomarker for cardiovascular disease risk. PLoS One 5: e9692. [Crossref]

Copyright: (C2015 Mooney KM. This is an open-access article distributed under the terms of the Creative Commons Attribution License, which permits unrestricted use, distribution, and reproduction in any medium, provided the original author and source are credited. 